\title{
Evaluation of setup by nurses of a novel click and go staple line reinforcement system
}

\author{
Crystal Ricketts and Esther Pollack \\ Ethicon, 4545 Creek Road, Cincinnati, OH 45242, USA
}

\begin{abstract}
Background: Staple line reinforcement (SLR) is used by surgeons to increase staple line strength and improve peri-operative haemostasis. However, currently marketed buttress materials require special attention in attachment to the staple anvil and cartridge and may come loose causing slipping, twisting, sliding and or bunching during manoeuvring of stapling procedures.
\end{abstract}

Objective: We conducted research with surgical scrub nurses to understand the impact of the recently developed ECHELON ENDOPATH ${ }^{\mathrm{TM}}$ SLR on ease of set up and application compared to the current available materials.

Methods: Twenty-nine (29) scrub / circulating nurses were given simulated loading exercises, which included loading the current brand(s) of SLR they use as well as the ECHELON ENDOPATH ${ }^{\mathrm{TM}}$ SLR. Each product was loaded two times. The process was evaluated for number of steps and measured for time and buttress attachment difficulties followed by questions on loading the buttress and waste.

Results: The ECHELON ENDOPATH ${ }^{\mathrm{TM}}$ SLR takes significantly less time to load versus Seamguard ${ }^{\circledR}$ or Peri-Strips Dry (median of $17.9 \mathrm{~s}$ vs. 80.9 s and 78.0 s, respectively, $\mathrm{p}<0.001)$. The ECHELON ENDOPATH ${ }^{\mathrm{TM}}$ SLR was assessed as having half the median number of steps required to load versus either Seamguard or Peri-Strips Dry. $100 \%$ of the survey responses agreed that 'compared to the loading of competitive products, the ECHELON ENDOPATH ${ }^{\mathrm{TM}}$ SLR is more efficient.'

Conclusion: The new buttress material comes with material affixed across the anvil and cartridge face of the stapler and maintains coverage during manipulations, set-up time was significantly reduced, and nurses felt the product was easier to load.

\section{Introduction}

Surgical stapling devices are used in open and laparoscopic surgeries allowing for rapid tissue transection approximation [1]. Surgical staplers are designed to provide haemostasis without causing ischemia or tearing of the tissue [2].

Staple line reinforcement was developed to strengthen the integrity of the staple line by means of a buttressing material that protects the tissue from staple injury and redistributes the pressure exerted by staples over a wider surface area [3-5]. By strengthening the staple line and redistributing the pressure, the buttress material reduces the risk for staple line failure and improves staple line haemostasis $[6,7]$.

Absorbable buttress is currently provided in the form of sleeves with suture lacing and rectangular flat strips that are manually attached to the surgical stapler anvil and cartridge. If the buttress sleeve lacing becomes un-zipped by pulling on the suture prior to firing, there is an elevated risk of the buttress material slipping, twisting, sliding or bunching up on the anvil and cartridge [8]. Gel adhesive is sometimes added to the reinforcement materials, creating an addition step [9]. Another available buttress consists of non-absorbable material, made from bovine pericardium and is applied in the form of rectangular flat strips to the staple cartridge prior to firing the stapler. The buttress is applied to both the cartridge and anvil. Traditionally gel is used to create a temporary bond between the buttress and the surgical stapler jaws until the stapler is positioned and fired. If the buttress moves unintentionally, the buttress may become irreversibly disabled. In addition, the existing buttress options can interact with trocars creating access issues as well as stick to itself, get curled up, caught in the trocar or the surgeon may have position issues on the tissue. This may cause unplanned wastage of buttress material, leading to additional time and related OR costs, along with cost of replacement buttress material.

A novel absorbable buttress was recently developed that allows for rapid and uncomplicated application [10]. The buttress is organized in a simple click-and-go applicator and made from synthetic absorbable materials that provide a high tensile strength along with rapid absorption (Figure 1). The buttress strengthens the staple line during healing and absorbs quickly yet adds only minimal thickness $(163 \mu \mathrm{m})$ to the staple line.

The present study compared the surgical nurse application of the novel buttress to the most commonly used commercially available staple line reinforcements to evaluate ease of set-up and application time.

\section{Material and methods}

The buttress materials evaluated in this study were ECHELON ENDOPATH $^{\mathrm{m}}$ Staple Line Reinforcement ECH60R (EER, Ethicon,

*Correspondence to: Crystal Ricketts, Ethicon, 4545 Creek Road, Cincinnati, OH 45242, USA, Tel: 513-337-3077, E- mail: cricket9@its.jnj.com

Key words: Buttress application, staple line reinforcement, nurses, staples

Received: January 07, 2020; Accepted: January 18, 2020; Published: January 24 2020 


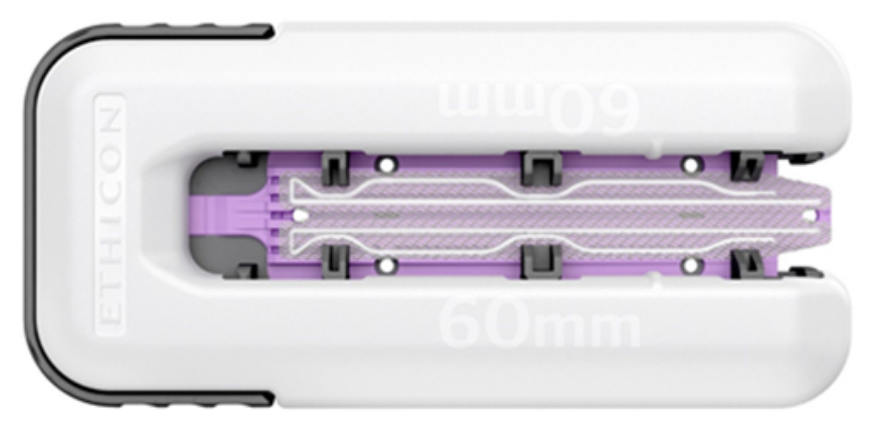

Figure 1. ECHELON ENDOPATHTM Staple Line Reinforcement Click and Go applicator

Inc., Cincinnati OH), GORE SEAMGUARD $^{\bullet}$ Bioabsorbable Staple Line Reinforcement 12BSGEC60A (GSG, W.L. Gore \& Associates, Flagstaff AZ), and PERI-STRIPS DRY Staple Line Reinforcement with VERITAS Collagen Matrix (PER, Baxter, Deerfield IL). EER consists of polyglactin 910 , the same material used in VICRYL suture (Ethicon, Inc.), and two layers of polydioxanone, the same material used in PDS suture film (Ethicon, Inc.), attached to the anvil and cartridge with a water soluble alkylene oxide copolymer (AOC) blend. GSG comes in a sleeve configuration and is made from a synthetic copolymer, polyglycolic acid:trimethylene carbonate (PGA:TMC), having an open, interconnected pore structure, that is specified to be absorbed within six to seven months. PER is prepared from bovine pericardium processed into a biocompatible, acellular, non-crosslinked collagen matrix. The staplers used were the Echelon Flex Powered Plus $60 \mathrm{~mm}$ Articulating Endoscopic Stapler (PSEE60A) with Endopath Echelon GST60G or GST60B staple reloads.

\section{Study design and participants}

Surgical scrub nurses were recruited to participate who had: 2-30 years of practice experience, currently have both scrub and circulating responsibilities, assisting with assembly of surgical devices including opening of device packaging, transfer to an OR sterile field, and loading of stapler cartridges, assisting in at least 5 laparoscopic or thoracoscopic (minimally invasive) procedures per month, assisting in at least 1 procedure per month in which an endoscopic stapler was used, loading buttress material onto a stapler in at least 4 procedures per month, and usage of or familiar with GSG or PER. Participating nurses signed a consent form and were assured that their participation in the study was voluntary and anonymized, and their responses were not individually identifiable. They received an honorarium for participation but were blinded to the identity of the study sponsor.

\section{Loading Simulations}

Participating nurses were first provided background information and a study brief. Subsequently they were provided with the EER Instructions for Use (IFU) and Optimal Device Performance Quick Guide (ODP) to review. The IFU's for GSG and PER were also made available. Nurses could refer to the IFU's and ODP at any time but did not receive any separate training on the EER device use. In random order, nurses were then asked to load the buttress onto the staplers with the EER or the SLR product they currently use (either GSG or PER). Each nurse then loaded the staplers with each product two times. The loading times and number of steps to load the staplers were recorded, and any attachment difficulties were documented. Following the simulation, each participating nurse was asked to provide feedback on the loading and related wastage of the products they tested. All activities were closely observed by a researcher who noted all results and observations.

Comparisons of number of steps and setup time were performed using the Kruskal-Wallis test with a significance level of $p<0.05$ for the difference between the three buttress groups.

\section{Results}

Twenty-nine participants were included in this study, 11 men and 18 women. The median age was 29 years, ranging from 24 years to 43 years. A breakdown of the demographics and clinical experience of group is provided in Table 1 split by their relative familiarity with exiting buttress products.

A summary of results is provided in Table 2. Setup with EER took a significantly fewer number of assessed steps than both GSG and PER ( $p$ $<0.001)$. The median number of assessed steps for GSG and PER were two times as many as for EER (Figure 2).

The corresponding setup time for EER was significantly shorter than for both GSG and PER $(p<0.001)$. Median load time for EER was 4.5 times faster than GSG and 3.5 times faster than PER. While there was a speed increase from the first trial to the second (Figure 3), even the fastest applications of GSG and PER were no faster than the slowest application time for EER.

Most nurses agreed that loading GSG and PSR was complex and frustrating compared to EER (Table 3). Nurses also were of the opinion that surgeons would have fewer issues with the EER buttress and that EER would be less likely to be wasted due to loading and positioning issues.

\section{Discussion}

The operating room is the financial hub of a hospital [11], accounting for up to $40 \%$ of a hospital's cost and $60-70 \%$ of revenue [12]. With operating room costs of approximately $\$ 25$ or more per minute [13], it is imperative that set-up and utilization of surgical devices is simple and effective, thus maximizing cost efficiency. Staplers have driven

Table 1. Nurse demographics

\begin{tabular}{|l|c|c|c|c|}
\hline Measure & GSG & PER & $\begin{array}{c}\text { GSG and } \\
\text { PER }\end{array}$ & Total \\
\hline $\mathrm{N}$ & 16 & 11 & 2 & 29 \\
\hline Gender & $10 \mathrm{~F} / 6 \mathrm{M}$ & $7 \mathrm{~F} / 4 \mathrm{M}$ & $1 \mathrm{~F} / 1 \mathrm{M}$ & $18 \mathrm{~F} / 11 \mathrm{M}$ \\
\hline Time in practice (yrs) & $10-25+$ & $10-25+$ & $15-24$ & $10-25+$ \\
\hline $\begin{array}{l}\text { No. of minimally invasive } \\
\text { procedures assisted per month }\end{array}$ & $5-25$ & $5-25$ & 25 & $5-25$ \\
\hline
\end{tabular}

Table 2. Summary of results

\begin{tabular}{|l|c|c|c|}
\hline Measure & EER & GSG & PER \\
\hline Number of applications & 58 & 38 & 25 \\
\hline Number of Assessed Steps & 2 & 4 & 4 \\
Median (Range) & $(1-6)$ & $(3-10)$ & $(3-12)$ \\
\hline Setup Time & $17.9 \mathrm{~s}$ & $80.9 \mathrm{~s}$ & $78.0 \mathrm{~s}$ \\
Median (Range) & $(10.0-34.1 \mathrm{~s})$ & $(35.6-203.8 \mathrm{~s})$ & $(34.0-300.0 \mathrm{~s})$ \\
\hline
\end{tabular}

Table 3. Nurses opinions of EER loading and waste versus loading of other buttress products

\begin{tabular}{|l|c|c|}
\hline Statement & Agree & Disagree \\
\hline Competitive products are complex and frustrating to load & $25(86 \%)$ & $4(14 \%)$ \\
\hline Using the EER will cause fewer issues for the surgeon & $28(97 \%)$ & $1(3 \%)$ \\
\hline $\begin{array}{l}\text { The amount of buttress that would be wasted will be less with the } \\
\text { EER compared to competitive products }\end{array}$ & $28(97 \%)$ & $1(3 \%)$ \\
\hline
\end{tabular}




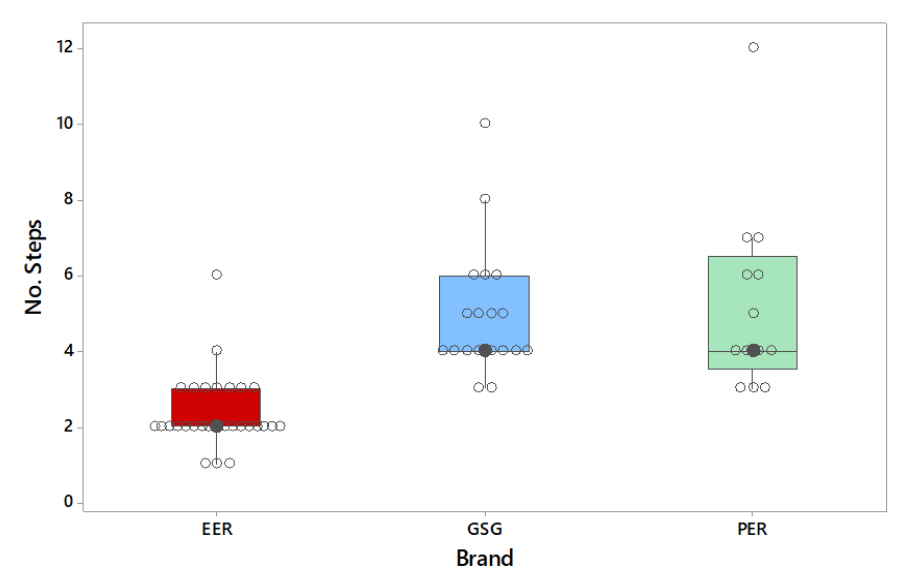

Figure 2. Boxplot of assessed number of steps for EER, GSG, and PER with individual values, interquartile region and median value

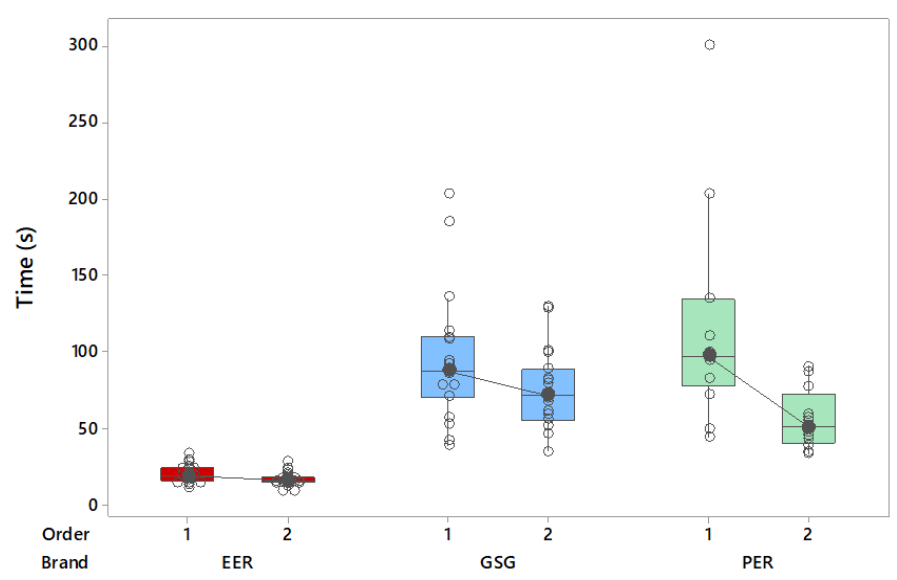

Figure 3. Boxplot of setup time for EER, GSG, and PER for each trial with individual values, interquartile region and median value

substantial increases in productivity over hand suturing, however optimal stapler usage can involve the use of staple line reinforcement, if the configuration does not mitigate the benefits achieved.

To our knowledge, this is the first published evaluation assessing the attachment of buttress material to a stapler cartridge and anvil. Significantly shorter application time and fewer buttress attachment challenges may have potential time-saving implications. Our results demonstrate that the EER buttress can be applied significantly faster than the GSG and PER buttress products. Nurses also reported that the EER required significantly fewer steps to load the buttress. While the number of buttress loading steps the nurses reported is different from the steps identified in each of the three buttress IFU's, the numbers trended in the same direction. The IFU for each device indicates that the number of steps for attaching the EER buttress is 4, GSG is 12 and PER is 16 steps.

The majority of nurses acknowledged there are loading issues with both the GSG and PER buttress material. Virtually all the nurses indicated that they thought there would be issues with GSG and PER buttress slippage, sticking etc. and they also indicated that there is wastage when these buttresses are attached to the stapler. A recent study 14 reported that approximately $13 \%$ of total operating room surgical costs were spent on unused or discarded supplies. Surgical supply waste is difficult to control because it is hard to predict the supplies a surgeon may need for a procedure, eliminating inefficient processes, and discarded buttresses may help to curb waste. The new
ECHELON ENDOPATH ${ }^{\text {su }}$ SLR is organized in an applicator with pre-loaded buttress attachment material designed to make buttress application uncomplicated and prevent the buttress material from moving or detaching from the anvil and/or cartridge. Further clinical testing of this novel staple line reinforcement is needed to assess the implication of time conservation and intraoperative efficiency, as well as the impact of the click- and-go applicator on post postoperative complications.

\section{Funding}

This study was sponsored by Ethicon Inc.

\section{Disclosure Statement}

$\mathrm{CR}$ and EP are employed by Ethicon Inc.

\section{References}

1. McGuire J, Wright I, Leverment J (1997) Surgical staplers: a review. J R Coll Surg Edinb 42: 1-9. [Crossref]

2. Kissin MW, Cox AG, Wilkins RA, Kark AE (1985) The fate of the EEA stapled anastomosis: a clinico-radiological study of 38 patients. Ann R Coll Surg Engl 67: 20. [Crossref]

3. Hendriks T, Vereecken TH, Hesp WL, Schillings PH, De Boer HH (1985) Loss of collagen from experimental intestinal anastomoses: early events. Exp Mol Pathol 42: 411-418. [Crossref]

4. Ahrendt GM, Gardner K, Barbul A (1994) Loss of colonic structural collagen impairs healing during intra-abdominal sepsis. Arch Surg 129:1179-1183. [Crossref]

5. Ahrendt GM, Tantry US, Barbul A (1996) Intra-abdominal sepsis impairs colonic reparative collagen synthesis. Am J Surg 171: 102-108. [Crossref]

6. Beart RW Jr, Kelly KA (1981) Randomized prospective evaluation of the EEA stapler for colorectal anastomoses. Am J Surg 141:143-147. [Crossref]

7. Högström H, Haglund U (1985) Postoperative decrease in suture holding capacity in laparotomy wounds and anastomoses. Acta Chir Scand 151: 533-535. [Crossref]

8. Consten EC, Dakin GF, Gagner M (2004) Intraluminal migration of bovine pericardial strips used to reinforce the gastric staple-line in laparoscopic bariatric surgery. Obes Surg 14: 549-554. [Crossref]

9. Gaertner WB, Hagerman GF, Potter MJ, Karulf RE (2010) Experimental evaluation of a bovine pericardium-derived collagen matrix buttress in ileocolic and colon anastomoses. J Biomed Mater Res B Appl Biomater 92: 48-54. [Crossref]

10. Wong JB, Henninger DD, Clymer JW, Ricketts CD (2019) A novel, easy-to-use staple reinforcement for surgical staplers. Medical Devices (Auckland, NZ). In press.

11. Rothstein DH, Raval MV (2018) Operating room efficiency. Paper presented at: Seminars in pediatric surgery.

12. Healey T, El-Othmani MM, Healey J, Peterson TC, Saleh KJ (2015) Improving operating room efficiency, part 1: general managerial and preoperative strategies. JBJS Rev 3. [Crossref]

13. Chen BP, Clymer JW, Turner AP, Ferko N (2019) Global hospital and operative costs associated with various ventral cavity procedures: a comprehensive literature review and analysis across regions. J Med Econ 22: 1210-1220. [Crossref]

14. Zygourakis CC, Yoon S, Valencia V, Boscardin C, Moriates C, et al. (2017) Operating room waste: disposable supply utilization in neurosurgical procedures. $J$ Neurosurg 126: 620-625. [Crossref]

Copyright: (C2020 Ricketts C. This is an open-access article distributed under the terms of the Creative Commons Attribution License, which permits unrestricted use, distribution, and reproduction in any medium, provided the original author and source are credited. 